University of Pennsylvania Carey Law School

Penn Law: Legal Scholarship Repository

Faculty Scholarship at Penn Law

$4-2-2020$

\title{
Sobering Up After the Seventh Inning: Alcohol and Crime Around the Ballpark
}

Jonathan Klick

University of Pennsylvania Law School

John M. MacDonald

University of Pennsylvania

Follow this and additional works at: https://scholarship.law.upenn.edu/faculty_scholarship

Part of the Criminal Law Commons, Criminology Commons, Criminology and Criminal Justice

Commons, Food and Drug Law Commons, Law and Economics Commons, Law and Society Commons, Policy Design, Analysis, and Evaluation Commons, and the Social Control, Law, Crime, and Deviance Commons

\section{Repository Citation}

Klick, Jonathan and MacDonald, John M., "Sobering Up After the Seventh Inning: Alcohol and Crime Around the Ballpark" (2020). Faculty Scholarship at Penn Law. 2263.

https://scholarship.law.upenn.edu/faculty_scholarship/2263

This Article is brought to you for free and open access by Penn Law: Legal Scholarship Repository. It has been accepted for inclusion in Faculty Scholarship at Penn Law by an authorized administrator of Penn Law: Legal Scholarship Repository. For more information, please contact PennlawIR@law.upenn.edu. 
Sobering Up After the Seventh Inning: Alcohol and Crime Around the Ballpark ${ }^{1}$

\author{
Jonathan Klick \\ John MacDonald
}

\begin{abstract}
Objectives: This study examines the impact of alcohol consumption in a Major League Baseball (MLB) stadium on area level counts of crime. The modal practice at MLB stadiums is to stop selling alcoholic beverages after the seventh inning. Baseball is not a timed game, so the duration between end of the seventh inning (last call for alcohol) and the end of the game varies considerably, providing a unique natural experiment that allows us to estimate the relationship between alcohol consumption and crime near a stadium on game days to non-game days and to areas around sports bars that fans also frequent but are not subject to alcohol restrictions after the seventh inning.
\end{abstract}

Methods: Crime data were obtained from Philadelphia for the period 2006-2015 and geocoded to the area around the MLB stadium as well as popular sports bars. We rely on difference-in-differences regression models to estimate the change in crime on home game days around the stadium as the game time extends into extra innings to other areas of the city and around sports bars in Philadelphia relative to days when the baseball team plays away from home.

Results: We found that when there are extra innings and more game-time after the seventh inning alcohol sales stoppage crime declines significantly around the stadium. The effects are largely driven by a reduction in assaults. The crime reduction benefit of the last call alcohol policy is undone when a complex of sports bars opens in the stadium parking lot in 2012. The results suggest that alcohol consumption during baseball games is a contributor to crime.

Conclusions: The findings provide further support for environmental theories of crime that note the congregation of people in places with excessive alcohol consumption is a generator of violent crime in cities. The consumption of alcohol in MLB stadiums appears to increase opportunities for people to get swept up into fights.

Key Words: Crime generators; Stadium, Alcohol and crime; Crime and Place

\footnotetext{
${ }^{1}$ We thank Jake Klick for excellent research assistance. We also thank Jonah Gelbach, Paul Heaton, Greg Ridgeway, and participants in the Penn Law Faculty and the Rotterdam Institute for Law and Economics workshops for comments. This work was funded by a grant from the Quattrone Center for the Fair Administration of Justice.
} 


\section{Introduction}

A growing body of literature finds that alcohol consumption is a contributor to crime (Carpenter \& Dobkin, 2011). Excessive alcohol consumption, for example, influences cognition and suppresses moral prohibitions that act as inhibitors of aggression (Exum, 2002). Alcohol consumption may also place individuals who drink in excess at greater risk for victimization, as criminal offenders may see inebriated people as easier targets for robbery and assault (Sherman, 1992). The consumption of alcohol in group settings may also fuel crime by increasing the number of social contacts, making people more talkative and increasing social interactions between motivated offenders and victims (Carpenter \& Dobkin, 2011). In general, evidence suggests that alcohol increases the risk of crime through offender, victim, and group setting channels.

It is not surprising then that alcohol-reduction policies have long been part of public health campaigns to reduce accidents, injuries, and violent crimes associated with its use (Fagan, 1990). The primary public policy approaches to reducing alcohol consumption have been to raise prices by imposing excise taxes on alcohol beverages, setting minimum age restrictions on the purchase and consumption of alcohol, limiting the times (hours and days of week) when alcohol beverages can be sold, and regulating the places where alcohol can be sold and consumed in public settings (Carpenter \& Dobkin, 2011).

While carefully done studies of alcohol restrictions around places generally suggest that reducing alcohol consumption lowers interpersonal crimes, these studies face standard identification problems. The place and time restrictions, for example, are often set up in response to concerns with crime and other negative externalities, or they may be implemented as part of a broader effort to curb the connection between alcohol and crime. Restrictions to close bars and taverns at earlier times of the day, or on given days of the week, are often a result of a concern with the crime and disorder facilitated at given locations that are hot spots for crime (Sherman, 1992). 
In England and Wales, for example, in 2005 the government removed restrictions on the closing time for bars to reduce crowding of intoxicated individuals on streets that were thought to be a primary contributor to assaults (Humprheys \& Eisner, 2010). More generally, regulations that seek to reduce consumption of alcohol in specific places may be endogenously related to concerns with crime and other negative externalities of excessive alcohol use. At the same time, there is an appreciable amount of literature suggesting that alcohol consumption in group settings, like sporting events, may be crime generators.

In this paper, we examine the impact of alcohol consumption during Major League Baseball (MLB) games on crime around a sports stadium. We rely on a novel natural experiment to provide credible estimates of the impact of alcohol consumption during MLB games on crime near a stadium. The MLB practice of ceasing to sell beer and other alcoholic beverages in stadiums at the end of the seventh inning provides an especially useful natural experiment to examine the impact of alcohol consumption on crime, because baseball is not a timed game. The game duration from the end of the seventh inning to the end of the game can be short or long. An inning could be as short as six pitches or it could go on indefinitely. Further, since there are no ties in MLB games, games can be as short as eight and a half innings or can go into effectively unlimited extra innings. This aspect of MLB games allows us to examine a wide range of time spans during which spectators are limited in their ability to drink alcohol. Thus, we can compare game days with non-game days when the game is at home or away, and when the time from the end of the seventh inning extends and fans who are in attendance are more likely to sober up.

We examine Philadelphia Phillies games because the Citizens Bank Park (CBP) stadium provides an additional quasi-experiment for us to exploit. In March 2012, the Xfinity Live! ${ }^{2}$ complex opened in the stadium parking lot. This entertainment venue contains several bars and restaurants that sell alcohol

\footnotetext{
${ }^{2}$ See https://www.xfinitylive.com
} 
until 2 a.m. each evening, effectively undoing any potential effect of the alcohol sale stoppage in the stadium at the end of the seventh inning.

We find that games that are relatively lengthy after the seventh inning and games with extra innings generate lower crime around $\mathrm{CBP}$, as compared to other areas around the city. For the average game, it appears that the alcohol sales restriction reduces assaults by around 50 percent. These effects are concentrated within the first hour after the game, with little additional crime reduction occurring after that, and in a relatively small area around CBP. We do not observe similar effects around a selection of popular sports bars in other areas of the city where no seventh inning restriction on alcohol sales applies. These effects largely vanish after the Xfinity Live! complex opened and allowed fans to continue to drink alcohol after the seventh inning in the stadium parking lot, further suggesting the link between the stadium alcohol restrictions and crime is causal.

In the following sections we briefly highlight prior literature on the effects of age, time, and place-based alcohol restrictions and sporting events on crime. We then discuss how theories of environmental criminology explain the mechanism through which alcohol consumption in places that gather people for legitimate social contact generates crime. This section is followed by an explanation of our unique methodology for identifying the effect of alcohol sales on crime during baseball games. Our results and analyses follow. Finally, we discuss the implications of this research for theories on criminality of places and crime prevention policy.

\section{Age, Time, and Place Restrictions on Alcohol}

Alcohol has long been thought to be a contributor to violent crime, with the most pronounced effects being for assaults. However, the historical empirical evidence for the physiological effects of intoxication as a direct cause of aggression has not be particularly convincing (see Fagan, 1990 for a review). More recently, scholars have turned to examining the impact of different alcohol restriction policies on crime. Studies have examined the effect of excise taxes imposed on alcohol sales, minimum 
age of alcohol access restrictions, and spatial/temporal restriction of alcohol availability. Multiple studies show when excise taxes on alcohol are raised alcohol consumption and violent crime drops (Cook \& Moore, 2001; Cook \& Moore, 1993; Matthews et al., 2006; Sivarajasingam et al., 2006). This literature is, however, limited because states seldom change excise tax rates on alcohol, so most of these effects are estimated from cross-sectional differences in taxes between states (see Cook \& Durrance, 2013 for an exception).

The empirical evidence of link between alcohol consumption and crime is the strongest from studies that examine age restrictions. Studies have taken advantage of the fact that the minimum alcohol drinking age of 21 in the United States is the only policy that discretely impacts people at this age. Several carefully done studies find that alcohol consumption jumps sharply at age 21 (see Carpenter \& Dobkin, 2001 for a review). Carpenter and Dobkin (2015), for example, find that arrests in California jump by a significant $6 \%$ for individuals after turning age 21 . This increase in arrests is mostly attributable to a rise in assaults, alcohol-related offenses, and nuisance crimes.

Studies on time and place restrictions also find that limiting alcohol sales to given times (days or hours of operation) and places also reduces crime (Carpenter \& Dobkin, 2011). Several studies have capitalized on natural experiments and examined what happens when there is a change in the times when alcohol can be sold, or the locations of alcohol establishments. Olsson and Wikstrom (1982) find that a 3-month prohibition of Saturday sales of alcohol in state-run liquor stores in Sweden reduced weekend public-order crimes, domestic disturbances, and assaults. Norstrom and Skog (2005), in a follow-up study, find that the repeal of the Saturday alcohol-sales ban in Sweden had no impact on assaults on Saturdays, despite a clear increase in alcohol sales. However, the number of assaults was so low at the time that this study may have been underpowered to detect effects. More recently, Heaton (2012) finds that the repeal of the Sunday alcohol-sales ban that was applied to only a set of jurisdictions in Virginia in 2004 and 2008 led to significant increases in minor and serious alcohol-related crimes on 
Sundays. The increase in alcohol-related offenses on Sunday also occurred in the afternoon when stores were open, suggesting that it is the consumption of alcohol shortly after stores open that generates the additional crime. Han et al. (2016), however, show that the lifting of Sunday sales prohibitions on alcohol in state-run stores in Pennsylvania has only a modest impact on crime in high poverty neighborhoods in Philadelphia.

Although the density and location of alcohol outlets are a known correlate of violent crime (Weisburd et al., 2012), most studies of alcohol outlets and violence are cross sectional. There are, however, a growing number of studies that examine what happens to crime after the opening or closing of alcohol outlets. Teh (2008), for example, finds that the opening of alcohol outlets in Los Angeles was associated with an increase in crimes around stores located in high poverty neighborhoods. Anderson et al. (2016) find that law changes in counties in Kansas that lifted prohibitions of selling alcohol to the public for on-premise consumption was associated with an increase in violent crime. The increase in violent crime also appears to be largest in counties that do not require a percentage of food to be sold at a bar, suggesting that the consumption of alcohol in bars is the primary contributor to the increase in violent crime. Evidence that opening bars is associated with an increase in violent crime is consistent with the widely-shared belief in criminology that bars are a common feature of violent crime hot spots in cities (Sherman et al., 1989; Weisburd et al., 2012; Ratcliffe, 2015; Tillyer, Wilcox, \& Walter, 2020). Large social events that involve alcohol consumption are also associated with increased risk of crime. Research on crime around college football stadiums, for example, shows that arrests for assaults and disorder offenses increase significantly on game days (Rees \& Schepel, 2009; Merlo et al., 2010). Several studies also find that crime increases in areas surrounding sports stadiums on home game days (Billings \& Depken, 2011; Kurland, 2014; Marie, 2016; Kurkland \& Johnson, 2019), when a stadium is present versus torn down (Vandeviver et al., 2019), and on days that sport stadiums are used 
(Campaniello, 2013; Munyo \& Rossi, 2013). ${ }^{3}$ Kurkland and Johnson (2019), for example, examine changes in crime levels around five soccer stadiums in the United Kingdom. They find that crime is higher on game days than other days of the week, and that the increase in crime is highest in neighborhoods closer to the stadiums and those with bars or restaurants.

While the presence of bars near sports stadiums appears to be a crime generator, studies on the criminality of places typically do not measure how crime varies with the availability of alcohol. The closest study that alludes to the link between alcohol consumption and crime around sporting events is Kurland and Johnson (2019), as they find that crime increases in neighborhoods with bars near soccer stadiums. However, this study cannot separate out the influence of alcohol consumption from the increase in the number of patrons who come to sports bars to watch the soccer games.

In general, studies that examine the impact of sports stadiums on crime cannot separate out whether the sporting events impact interpersonal crimes like assaults because of gathering more people together, or because of the excessive alcohol consumption. At college football games, for example, alcohol sales are already generally banned in stadiums, so fans tend to drink alcohol just outside the stadium prior to the game and subvert the impact of sales restrictions. There are, however, criminological theories that explain why limiting alcohol sales in specific times and places may help thwart crime in settings that bring groups of people together for social contact.

\section{Environmental Criminology: Situational Opportunities Theories}

Environmental criminology provides a clear framework for understanding how the place in which alcohol is consumed can be a facilitator of crime (Wilcox \& Gialopsos, 2015). Environmental criminology assumes that crime patterns in space are distributed according to how the environment of a place at a given time influences the volume and types of criminal opportunities. Theories that fall within

\footnotetext{
${ }^{3}$ Kurland and Johnson (2019) provide detailed review of this literature.
} 
the framework of environmental criminology articulate mechanisms by which alcohol consumption in specific places may interact to generate crime.

Alcohol consumption affects cognition and vulnerability. Impaired individuals, for example, are more likely to be aggressive or appear vulnerable to would-be offenders. Clarke's (1995) situational crime prevention theory argues that offending may be influenced by alcohol consumption, as excessive alcohol consumption makes people myopic and may change their perceptions of the crime opportunity structure. This may be particularly true in the context of alcohol-fueled offenses such as assaults, where group dynamics of excessive drinking may lead to more potential opportunities for fights. Similarly, there may be dynamics of places at a given time of day (e.g., when bars close) where an increase in the number of inebriated people on the streets provides a target-rich environment for potential confrontations. Weisburd et al. (1992), for instance, find that calls about public drinking are one of the main correlates of robbery hot spots. Multiple studies find that excessive alcohol consumption prior to closing time and crowding in the streets after bars close are risk factors for assaults (Graham \& Homel, 2012).

Cohen and Felson's (1979) routine activity theory also explains how the movement of people between places influences the presence of motivate offenders, suitable targets, and guardianship to thwart crime. Alcohol consumed in social settings, like sports stadiums and bars, may create larger flows of inebriated people in the streets and provide more opportunities for robberies and assaults between people. Recreational drinking of alcohol at places where people gather to watch sporting events may also generate more public-order offenses and assaults by increasing the number of motivated offenders, as inhibitions against violence and disorderly behavior are lowered when people are intoxicated.

Within the context of places themselves, crime pattern theory provides a clear typology for explaining how the activity patterns around places that gather people together for legitimate uses, like watching a sporting event in a bar or stadium, becomes a crime generator. As Brantingham and 
Brantingham (1995) explain, sports stadiums and other venues that bring large numbers of people together for reasons "unrelated to any particular level of criminal motivation" can become crime generators by creating sufficient concentrations of people in a setting that allows people to "exploit criminal opportunities" (pp. 7-8). Intoxicated people in greater numbers near each other provide more available opportunities for interpersonal crimes like assaults, as drunk individuals get "swept up into fights" (p.11). Rowdy bars are particularly prone environments for assaults to occur (Graham et al., 2006).

In summary, environmental criminology perspectives suggest alcohol consumption in group settings may fuel crimes of interpersonal violence like assaults.

\section{Last Call for Alcohol Sales}

Although Major League Baseball (MLB) does not mandate rules regarding the sale of alcohol at individual sports stadiums, most MLB teams adopt a host of sales restrictions. ${ }^{4}$ The focus of this paper is the rule about when alcohol sales cease during baseball games. All MLB stadiums stop selling alcohol prior to the end of the game. The Philadelphia Phillies ballpark, Citizens Bank Park (CBP), ceases sales at the end of the seventh inning. ${ }^{5}$ This is the most common policy among MLB teams, though some stop sales as late as the end of the eighth inning (e.g., Baltimore Orioles for concession stand sales) and others as early as the middle of the seventh inning (e.g., New York Yankees for concession stand and hawker sales). Other alcohol restrictions include limits on how many alcoholic drinks an individual can purchase at a time (generally two, as is the case for the Phillies) and maximum cup sizes ( $24 \mathrm{oz}$. for the Phillies).

\footnotetext{
${ }^{4}$ Major League Baseball is a member of Team Coalition (along with the other major U.S. sports leagues) which does provide a list of best practices regarding alcohol sales. See https://teamcoalition.org/training/policies/ ${ }^{5}$ See https://fansdontletfansdrivedrunk.org/team/mlb/philadelphia-phillies/\#1442768220251-8edb53aabec4d832-ba39ff22-02f5
} 
The logistics of an MLB baseball game seventh inning sales cut off creates quasi-randomization regarding how long people are prohibited from purchasing alcohol. Because baseball is not a timed game, the duration from the end of the seventh inning to the end of the game (when spectators generally leave the ballpark) is variable game-to-game.

Putting aside games affected by rain delays (which we exclude from our analysis) which can cause a game to end during any inning, a baseball game can have as few as eight and a half innings (when the home team is winning after the visiting team bats in the top of the $9^{\text {th }}$ inning) or can extend to effectively limitless innings since a baseball game cannot end in a tie. ${ }^{6}$ Beyond that, an inning itself has no fixed time duration, ending only after each team has recorded three outs. The minimum number of pitches that could end an inning is six, although that has not happened. ${ }^{7}$ On the other end of things, the number of pitches thrown in an inning is limitless. For example, in the top of the second inning in a July 26, 1999 San Francisco Giants game, pitcher Russ Ortiz threw 63 pitches to retire the St. Louis Cardinals and then Jose Jimenez threw 32 pitches to retire the Giants in the bottom of the inning. ${ }^{8}$ In one instance, a pitcher threw 21 pitches to get a single batter out. ${ }^{9}$ Further, there is no restriction on how long it takes a pitcher to throw a pitch. ${ }^{10}$

This variability inherent in the game of baseball allows us to examine changes in crime when spectators are prohibited from buying alcohol for a long period of time versus games where the prohibition ends up being quite short. Focusing on the Phillies CBP stadium also allows us to exploit an

\footnotetext{
${ }^{6}$ The longest game in MLB history was 25 innings and lasted eight hours and six minutes on May 8, 1984 between Chicago White Sox and the Milwaukee Brewers.

${ }^{7}$ There have been fewer than 200 total instances where an individual pitcher has thrown just three pitches in an inning, but none of these instances occurred in the same inning by two opposing pitchers. See https://www.baseball-almanac.com/feats/3 pitch inning.shtml ${ }^{8}$ https://www.baseball-reference.com/boxes/SFN/SFN199907260.shtml

${ }_{9}^{9}$ San Francisco Giant Brandon Belt faced a total of 21 pitches from Los Angeles Angels pitcher Jaime Barria in the $1^{\text {st }}$ inning of the April 22, 2018 match. See https://www.baseball-reference.com/boxes/ANA/ANA201804220.shtml ${ }^{10}$ The advanced statistic PACE provides some measure of how fast pitchers work. In some years, based on the PACE metric, the difference between the fastest and slowest working pitchers may be as much as 20 seconds per throw.
} 
additional source of variation. In March of 2012, the Xfinity Live! entertainment complex was opened on the corner of Pattison Avenue and $11^{\text {th }}$ Street directly opposite the Southwest corner of CBP, about 300 feet from the ballpark gates in what was previously part of the stadium parking lot.

Xfinity Live! includes, among other bars and restaurants, the Broad Street Bullies Pub and the Victory Beer Hall. These establishments serve alcohol nightly until 2 a.m. Because these places effectively undo the CBP seventh inning cut-off, as spectators can either leave a game early and walk 0.05 miles to continue drinking or, if they stay in the ballpark for the final out, fans can easily resume drinking in what is basically the ballpark's parking lot. Given this, if alcohol consumption in stadiums increases crime, we should see any effect of the ballpark alcohol cut off on crime diminish substantially after Xfinity Live! opens in the 2012 baseball season.

\section{Design and Empirical Methods}

In this study, we leverage the difference in crime around the Citizens Ball Park (CBP) in Philadelphia between 2006 and 2015 to examine the effect of alcohol consumption during baseball games on surrounding crime rates. To estimate the impact of alcohol consumption we employ a differences-indifferences design, which compares changes in crime around CBP on home game days when they extend into extra innings to away game days and to other areas of Philadelphia not located near CBP. We estimate changes in total reported crime, assaults, theft, liquor violations, and disorderly conduct. We focus on these subcategories of total crime as they are most likely to be influenced by excessive alcohol consumption in stadiums. We construct the counts of crimes at different geographic units of analysis (Police Service Area, roadway network, and Census Block) for each day of observation. Our primary specification estimates the count of crime on a given game day within a specific geographic unit around the CPB according to the following form:

$Y_{\mathrm{it}}=\beta_{0}+\beta_{1}$ Home Game $_{t} *$ Extra Innings $_{t} * C B P_{i}+\beta_{2}$ Home Game $_{t} * C B P_{i}+$ $\beta_{3}$ Extra Innings $t_{t} \mathrm{CBP}_{i}+\alpha_{t}+\delta_{i}+\varepsilon_{i t}$ (1) 
For model (1) we analyze the relationship between the home game day and presence of extra innings at different levels of geography (geographic units denoted by $i$ ) around CBP for a given day (denoted by $t$ ) on the count of crime $\left(Y_{i t}\right)$. The interaction term $\left(\beta_{1}\right)$ provides the treatment effect estimate of the extra innings during home game days on crime surrounding CBP stadium. The regression model also accounts for potentially higher crime in the CBP area on home game days $\left(\beta_{2}\right)$ generally (i.e., whether there are extra innings or not), and it accounts for potentially higher crime around CBP during extra-innings games $\left(\beta_{3}\right)$ even when the game is away. This latter effect is necessary since we define the span of a day as running from the time of the first pitch to the time of the last out plus one hour. Because of this, extra inning game days will mechanically generate more crime simply because the window of time is longer. The model also includes separate fixed effect dummies for every day in the sample to control for period effects, and separate fixed effects for each geographic unit to allow for differential crime baselines by area.

We use only days during the baseball regular season (April - October) and drop days entirely if the Philadelphia Phillies played a double header ( 24 days) or a game that had any rain delay time (54 games). Standard errors are clustered at the location level to account for dependence within areas.

\section{Data}

We use incident report based crime data provided by the Philadelphia Police Department. ${ }^{11}$ These data cover each crime reported in the city and include both location data (latitude and longitude as well as street block) and the date and time the crime is reported. The data are available starting in 2006 and are updated regularly. Our analyses cover the 2006 through the 2015 baseball season. We aggregate total crime counts and subcategories (assault, theft, liquor violations, disorderly conduct) to the Philadelphia

\footnotetext{
${ }^{11}$ https://www.opendataphilly.org/dataset/crime-incidents
} 
Police Department's Police Service Areas (PSA) as our primary geographic unit of analysis. ${ }^{12}$ We include the entire PSA in which the CBP stadium is located (District 3; PSA 3) ) $^{13}$ as our primary treatment area. In separate analyses, we also aggregate crime counts on game days to the Census Block level ${ }^{14}$ to focus more tightly on the area just around the stadium. The Census designation effectively covers the stadium and its nearby parking lots, but this means the eastern boundary is coincident with the wall of the stadium and, therefore, does not capture any crimes committed to the east of the stadium. Although the Census blocks are a sensible unit for measuring crime around $\mathrm{CBP}$, in addition to this eastern boundary problem, it also includes the Philadelphia Eagles practice facility which is inaccessible to the public (West of Broad Street).

To provide an additional geographic measure of crime, we also aggregate crime to the natural transportation nodes around CBP as another treatment unit. Three of these boundaries are major highways or arterial roads (I-95 is 1900 feet to the South of the CBP southern wall, I-76 is 1500 feet to the North of the CBP northern wall, and Broad Street is 1500 feet to the West of the CBP western wall). The approach of counting crime around a node network is consistent with studies that use road networks to examine the spatial patterns of crime (Davis \& Johnson, 2015). Only the eastern boundary has no comparable transportation border. For the eastern boundary, we measured 1500 feet from the eastern CBP wall. Any crime that occurred within the CBP PSA but outside of this boundary was assigned to a separate geographic unit. We perform analyses on this natural CBP geographic unit as compared to all other PSAs in the city.

\footnotetext{
12 There are 66 PSAs in Philadelphia. PSAs are police patrol boundaries within police districts that were designed to be reflective of neighborhood boundaries as part of the Philadelphia Police Department's shift to community police.

${ }^{13}$ https://www.phillypolice.com/districts/3rd/index.html

${ }_{14}$ Citizens Bank Park is located in Census Tract Code 9806.00; see https://www2.census.gov/geo/maps/dc10map/tract/st42_pa/c42101_philadelphia/DC10CT_C42101_003.pdf.
} 
To provide an additional comparison, we also measured boundaries of comparable dimensions around popular sports bars in Philadelphia. These bars draw Phillies fans on game nights but do not stop selling alcoholic beverages at the end of the seventh inning. This comparison allows us to examine whether game-specific dynamics (e.g., especially exciting games) affect crime among drinking sports fans independent of the alcohol service policy in ways that might be coincidentally related to game duration. Admittedly, any choice of what sports bars to compare with CBP will be arbitrary. While the choice of sports bars is ad hoc, any game-induced drinking and crime effect should be exhibited around the most sports bars.

To aggregate across time, we defined the relevant time period for each day's crime as being the time of the game's first pitch through one hour after the end of the game. ${ }^{15}$ For days where no game was played, we define the time window as 7 p.m. to 11 p.m. which approximates the standard window for game days. In subsequent analyses, we expanded this window to three hours after the end of the game and five hours after the end of the game. For away games, which we use as comparators in some analyses, we used the same timing approach but shift the time if the game was played outside of the Eastern Time Zone. We drop days in which double headers are played and those that were delayed because of rain. ${ }^{16}$ We only examine days during baseball's regular season, omitting pre-season games and playoff games.

The available data on baseball games does not provide a specific time when innings begin (other than the $1^{\text {st }}$ ) or end (other than the last). There is no way from public data to measure how much of a game's duration occurs after the seventh inning. To address this limitation, we measure game length

\footnotetext{
${ }^{15}$ The generally available baseball game data have a specific time of first pitch and a total time of game from the first pitch to the final out, but do not include a time of the last out. To determine the time of the last out, we added the game time to the first pitch time.

${ }^{16}$ The generally available baseball statistics do not note which games have rain delays. We purchased information on rain delay time from Stats Perform (formerly Stats LLC), a data provider for MLB. From 2006-2015, the Phillies played 54 games where there was non-zero rain delay time.
} 
using two proxies. First, we examine whether the game goes into extra innings because the score was tied at the end of the $9^{\text {th }}$ inning. Extra-inning games are substantially longer, clocking in at an average of 226 minutes compared to 172 minutes for games without extra innings. The difference in almost one hour, allowing an average person the ability to process about one more alcoholic drink, ${ }^{17}$ suggesting that some share of spectators could sober up and reduce the effects of alcohol consumption crime. Second, we include a measure of the number of pitches thrown after the seventh inning as a proxy for the length of the game after alcohol sales cease. The number of pitches thrown in an inning is a good proxy for duration, as the correlation coefficient between the duration of a game and total pitches thrown exceeds 0.90 , and complete pitch counts by inning are publicly recorded.

\section{Descriptive Statistics}

Table 1 provides descriptive statistics for crime counts per day the CBP PSA and all other PSAs for both the baseball season period and year-round. While crime is generally only a little higher during baseball season throughout the city, the increase is much larger in the CBP PSA.

\begin{tabular}{|c|c|c|c|c|}
\hline \multirow{2}{*}{\multicolumn{5}{|c|}{$\begin{array}{l}\text { Table 1: Daily Crime Descriptive Statistics (All Philadelphia PSAs v. Citizens Bank Park PSA) } \\
\text { Time Period Equals Game Start Time Through Game End Time Plus One Hour for Game Days }\end{array}$}} \\
\hline & & & & \\
\hline \multicolumn{5}{|c|}{ Time Period Equals 7 p.m. through 11 p.m. for Non-Game Days } \\
\hline \multicolumn{5}{|c|}{ (Standard Deviations in Parentheses) } \\
\hline & All PSAs & CBP PSA & All PSAs & CBP PSA \\
\hline & \multicolumn{2}{|c|}{ Year Round } & \multicolumn{2}{|c|}{ Baseball Season } \\
\hline Total Crime & $\begin{array}{c}1.78 \\
(1.97)\end{array}$ & $\begin{array}{c}2.79 \\
(2.32)\end{array}$ & $\begin{array}{c}1.88 \\
(2.08)\end{array}$ & $\begin{array}{c}3.15 \\
(2.44)\end{array}$ \\
\hline Assault & $\begin{array}{c}0.29 \\
(0.60)\end{array}$ & $\begin{array}{c}0.49 \\
(0.77)\end{array}$ & $\begin{array}{c}0.32 \\
(0.63)\end{array}$ & $\begin{array}{c}0.56 \\
(0.84)\end{array}$ \\
\hline Theft & $\begin{array}{c}0.18 \\
(0.45)\end{array}$ & $\begin{array}{c}0.26 \\
(0.51)\end{array}$ & $\begin{array}{c}0.19 \\
(0.47)\end{array}$ & $\begin{array}{c}0.30 \\
(0.55)\end{array}$ \\
\hline Liquor Violations & $\begin{array}{c}0.01 \\
(0.21)\end{array}$ & $\begin{array}{c}0.13 \\
(0.68)\end{array}$ & $\begin{array}{c}0.01 \\
(0.25)\end{array}$ & $\begin{array}{c}0.20 \\
(0.83)\end{array}$ \\
\hline Disorderly Conduct & $\begin{array}{c}0.04 \\
(0.25)\end{array}$ & $\begin{array}{c}0.10 \\
(0.36)\end{array}$ & $\begin{array}{c}0.04 \\
(0.25)\end{array}$ & $\begin{array}{c}0.13 \\
(0.41)\end{array}$ \\
\hline
\end{tabular}

\footnotetext{
${ }^{17}$ See, for example, https://www.nhs.uk/common-health-questions/lifestyle/how-long-does-alcohol-stay-in-yourblood/
} 
Note: Data provided by Philadelphia Police Department and available publicly at

https://www.opendataphilly.org/dataset/crime-incidents. Data cover 2006-2015. Baseball Season covers April through October. Only regular season games are included in game data. Game days that include a double header or games with rain delay time are excluded from the data ( $X$ out of $Y$ total games). For games played in the Eastern time zone, the time period covered is the time of the first pitch to the end of the game plus one hour. For games played in different time zones, the time period covered is the time of the first pitch converted to Eastern time through the end of the game plus one hour. For non-game days, the time period covers 7:00 p.m. to 11 p.m.

A comparison of crime in the CBP PSA during home and away games might be informative, since

the cut-off policy is only relevant for home games. That said, since the time window for aggregating crimes is dependent on the length of the game (and if baseline crime rates differ according to the time of day), it is important that the length of a game and start times be comparable. Table 2 provides descriptive statistics about Phillies games during our sample period broken down by home and away games. For most measures, home and away games are comparable in length, number of pitches after the seventh inning, and start time.

\begin{tabular}{|l|c|c|}
\hline \multicolumn{2}{|c|}{ Table 2: Descriptive Statistics for Phillies Games (Home v. Away) } \\
\hline \multicolumn{2}{|c|}{ (Standard Deviations in Parentheses) } \\
\hline Phillies' Record & Home & Away \\
& 0.545 & 0.503 \\
& $(0.498)$ & $(0.500)$ \\
\hline Total Pitches - mean & 293 & 294 \\
& $(45)$ & $(41)$ \\
\hline Pitches After $7^{\text {th }}$ Inning - mean & 68 & 68 \\
& $(37)$ & $(32)$ \\
\hline Duration in Minutes - mean & 178 & 178 \\
& $(30)$ & $(28)$ \\
\hline Attendance - mean & 38,440 & 31,735 \\
& $(8,293)$ & $(9,793)$ \\
\hline Start Time - mode & $7: 07$ p.m. & $7: 09$ p.m. \\
\hline Games - total & 741 & 778 \\
\hline Extra Inning Games - total & 75 & 81 \\
\hline Note: Data compiled from https://www.baseball-reference.com/teams/PHI/ game logs. Data cover \\
2006-2015. Only regular season games are included in game data. Game days that include a double \\
header or games with rain delay time are excluded from the data. \\
\hline
\end{tabular}

Table 3 shows crimes per day for home and away games. While there is not much difference throughout Philadelphia in comparing crime during home games and during away games, the crime 
appears to be $46 \%$ higher in the CBP PSA during home game days (3.87) than during days when the game is away (2.65). This pattern of elevated crime counts around CPB on home game days is also apparent for assaults, theft, liquor violations, and disorderly conduct.

\begin{tabular}{|c|c|c|c|c|}
\hline \multicolumn{5}{|c|}{ Table 3: Gameday Daily Crime Descriptive Statistics (Home Game Days v. Away Game Days) } \\
\hline \multicolumn{5}{|c|}{ Time Period Equals Game Start Time Through Game End Time Plus One Hour } \\
\hline \multicolumn{5}{|c|}{ (Standard Deviations in Parentheses) } \\
\hline & All PSAs & CBP PSA & All PSAs & CBP PSA \\
\hline & \multicolumn{2}{|c|}{ Home Game Days } & \multicolumn{2}{|c|}{ Away Game Days } \\
\hline Total Crime & $\begin{array}{c}1.92 \\
(2.16)\end{array}$ & $\begin{array}{c}3.87 \\
(2.70)\end{array}$ & $\begin{array}{c}1.85 \\
(2.07)\end{array}$ & $\begin{array}{c}2.65 \\
(2.22)\end{array}$ \\
\hline Assault & $\begin{array}{c}0.32 \\
(0.63)\end{array}$ & $\begin{array}{c}0.63 \\
(0.89)\end{array}$ & $\begin{array}{c}0.31 \\
(0.62)\end{array}$ & $\begin{array}{c}0.48 \\
(0.78)\end{array}$ \\
\hline Theft & $\begin{array}{c}0.19 \\
(0.47)\end{array}$ & $\begin{array}{c}0.33 \\
(0.59)\end{array}$ & $\begin{array}{c}0.20 \\
(0.47)\end{array}$ & $\begin{array}{c}0.28 \\
(0.54)\end{array}$ \\
\hline Liquor Violations & $\begin{array}{c}0.02 \\
(0.35)\end{array}$ & $\begin{array}{c}0.54 \\
(1.31)\end{array}$ & $\begin{array}{c}0.01 \\
(0.20)\end{array}$ & $\begin{array}{c}0.01 \\
(0.12)\end{array}$ \\
\hline Disorderly Conduct & $\begin{array}{c}0.04 \\
(0.26)\end{array}$ & $\begin{array}{c}0.24 \\
(0.54)\end{array}$ & $\begin{array}{c}0.04 \\
(0.24)\end{array}$ & $\begin{array}{c}0.07 \\
(0.30)\end{array}$ \\
\hline \multicolumn{5}{|c|}{$\begin{array}{l}\text { Note: Data provided by Philadelphia Police Department and available publicly at } \\
\text { https://www.opendataphilly.org/dataset/crime-incidents. Data cover 2006-2015. Baseball Season } \\
\text { covers April through October. Only regular season games are included in game data. Game days that } \\
\text { include a double header or games with rain delay time are excluded from the data. For games played } \\
\text { in the Eastern time zone, the time period covered is the time of the first pitch to the end of the game } \\
\text { plus one hour. For games played in different time zones, the time period covered is the time of the } \\
\text { first pitch converted to Eastern time through the end of the game plus one hour. }\end{array}$} \\
\hline
\end{tabular}

Table 4 provides descriptive statistics for crime in the CBP PSA comparing 9 inning games to extra innings, and home and away games. The home and away comparison is important because the extra-inning games will include a longer time window in total, which could mechanically increase the crime counts. The difference in counts between extra-inning games and 9 inning games for away games provides some calibration for this expanding window effect.

\begin{tabular}{|c|c|c|c|c|}
\hline \multicolumn{5}{|c|}{ Time Period Equals Game Start Time Through Game End Time Plus One Hour } \\
\hline \multicolumn{5}{|c|}{ (Standard Deviations in Parentheses) } \\
\hline & 9 Innings & Extra Innings & 9 Innings & Extra Innings \\
\hline & \multicolumn{2}{|c|}{ Home Game Days } & \multicolumn{2}{|c|}{ Away Game Days } \\
\hline Total Crime & 3.81 & 4.40 & 2.57 & 3.33 \\
\hline
\end{tabular}




\begin{tabular}{|l|c|c|c|c|}
\hline & $(2.60)$ & $(3.42)$ & $(2.21)$ & $(2.26)$ \\
\hline Assault & 0.62 & 0.72 & 0.45 & 0.77 \\
& $(0.89)$ & $(0.83)$ & $(0.73)$ & $(1.09)$ \\
\hline Theft & 0.33 & 0.32 & 0.27 & 0.30 \\
& $(0.59)$ & $(0.62)$ & $(0.54)$ & $(0.53)$ \\
\hline Liquor Violations & 0.54 & 0.55 & 0.01 & 0.02 \\
& $(1.27)$ & $(1.69)$ & $(0.11)$ & $(0.16)$ \\
\hline Disorderly Conduct & 0.23 & 0.33 & 0.07 & 0.05 \\
& $(0.53)$ & $(0.60)$ & $(0.30)$ & $(0.22)$ \\
\hline
\end{tabular}

Note: Data provided by Philadelphia Police Department and available publicly at https://www.opendataphilly.org/dataset/crime-incidents. Data cover 2006-2015. Baseball Season covers April through October. Only regular season games are included in game data. Game days that include a double header or games with rain delay time are excluded from the data. For games played in the Eastern time zone, the time period covered is the time of the first pitch to the end of the game plus one hour. For games played in different time zones, the time period covered is the time of the first pitch converted to Eastern time through the end of the game plus one hour. Data only cover the PSA that includes Citizens Bank Park.

While crime in the CBP PSA is higher at home for extra-inning games than it is for 9 inning games, the proportional increase of $15 \%$ is about half as large $(4.4 / 3.81=1.15)$ as the same comparison for away game days (3.33/2.57=1.30). Looking at specific crimes, it appears as though assaults are the most affected crime category. Assaults rise by only $16 \%$ on home game days with extra innings compared to $71 \%$ for away games with extra innings. This is consistent with much of the literature previously reviewed that suggests assaults are particularly sensitive to alcohol consumption and the policies used to influence that consumption. These increases in assault, however, is only an illustration and does not provide any strong identification.

\section{Results}

Table 5 provides results from our regression specifications of total crime, assaults, thefts, liquor violations and disorderly conduct at the PSA level and how they vary with different specifications. The results show a general decline in crime around the CPB stadium on days when home games go into extra innings, but we cannot reject the null hypothesis of no difference at a $p<0.05$. Relative to the average number of assaults in the CBP PSA on days when the home game does not go into extra innings, this 
represents a decline of about one quarter. Thefts and liquor violations also decline by a statistically significant amount of around $p=.10$ and $p .=.02$ respectively. Disorderly conduct violations, however, increase significantly.

Recent work ${ }^{18}$ suggests reasons to be concerned with standard inference approaches when there are few treatment areas in difference-in-differences estimators, likely resulting in an underrejection of the null hypothesis. With this in mind, we present two-sided $10 \%$ critical values $^{19}$ that arise from running the regressions repeatedly (65 times; one for each PSA) and using each non-CBP PSA as a placebo treatment geographic unit. This approach is often referred to as randomization inference (MacKinnon \& Webb, 2018) or permutation tests for generating a reference distribution, and date back to Fisher's idea of exact inference (Ernst, 2004). ${ }^{20}$

\begin{tabular}{|c|c|c|c|c|c|}
\hline \multicolumn{6}{|c|}{ Table 5: Effect of Extra Innings on Crime } \\
\hline \multicolumn{6}{|c|}{$\begin{array}{c}\text { (Standard Errors Clustered at PSA Level) } \\
\{\text { Two-Sided } 10 \% \text { Critical Values from Placebo Regressions }\}\end{array}$} \\
\hline & \multicolumn{5}{|c|}{ Dependent Variable [Mean for CBP PSA Below] } \\
\hline & Total Crime & Assaults & Theft & Liquor & Disorder \\
\hline & [3.15] & {$[0.56]$} & {$[0.30]$} & {$[0.20]$} & [0.13] \\
\hline & \multicolumn{5}{|c|}{$\begin{array}{c}\text { Extra Inning * Home Game * CBP PSA Coefficients } \\
\text { By Specifications/Sample Restrictions }\end{array}$} \\
\hline $\begin{array}{l}\text { All Days Included; } \\
\text { No Length of Game } \\
\text { Controls }\end{array}$ & $\begin{array}{c}-0.06 \\
(0.05) \\
\{-0.61,0.66\}\end{array}$ & $\begin{array}{c}-0.17 * * * \\
(0.01) \\
\{-0.17,0.17\}\end{array}$ & $\begin{array}{c}-0.03 * * * \\
(0.01) \\
\{-0.18,0.14\}\end{array}$ & $\begin{array}{c}-0.01 * * \\
(0.00) \\
\{-0.03,0.06\}\end{array}$ & $\begin{array}{c}0.13^{* * *} \\
(0.01) \\
\{-0.09,0.09\}\end{array}$ \\
\hline $\begin{array}{l}\text { Only Game Days } \\
\text { Included; No Length } \\
\text { of Game Controls }\end{array}$ & $\begin{array}{c}-0.15^{* * *} \\
(0.05) \\
\{-0.57,0.66\} \\
\end{array}$ & $\begin{array}{c}-0.22 * * * \\
(0.01) \\
\{-0.17,0.17\} \\
\end{array}$ & $\begin{array}{c}-0.04 * * * \\
(0.01) \\
\{-0.17,0.14\} \\
\end{array}$ & $\begin{array}{c}-0.01 * * * \\
(0.00) \\
\{-0.04,0.05\}\end{array}$ & $\begin{array}{c}0.14^{* * *} \\
(0.01) \\
\{-0.09,0.09\} \\
\end{array}$ \\
\hline $\begin{array}{l}\text { All Days Included; } \\
\text { Length of Game } \\
\text { Controls Included }\end{array}$ & $\begin{array}{c}-0.39 * * * \\
(0.06) \\
\{-0.84,0.57\}\end{array}$ & $\begin{array}{c}-0.21 * * * \\
(0.02) \\
\{-0.22,0.19\}\end{array}$ & $\begin{array}{c}-0.07^{* * *} \\
(0.01) \\
\{-0.20,0.12\}\end{array}$ & $\begin{array}{c}-0.13 * * * \\
(0.01) \\
\{-0.03,0.09\}\end{array}$ & $\begin{array}{c}0.06^{* * *} \\
(0.01) \\
\{-0.10,0.09\}\end{array}$ \\
\hline $\begin{array}{l}\text { Only Game Days } \\
\text { Included; Length of }\end{array}$ & $\begin{array}{c}-0.39 * * * \\
(0.05)\end{array}$ & $\begin{array}{c}-0.28 * * * \\
(0.02)\end{array}$ & $\begin{array}{c}-0.03 * * * \\
(0.01)\end{array}$ & $\begin{array}{c}-0.13^{* * *} \\
(0.01)\end{array}$ & $\begin{array}{c}0.10^{* * *} \\
(0.01)\end{array}$ \\
\hline
\end{tabular}

\footnotetext{
${ }^{18}$ See, for example, Conley and Taber (2011); Cameron, Gelbach, and Miller (2008); and MacKinnon and Webb (2019).

${ }^{19}$ We present the placebo coefficients, though the inferences are generally unchanged if we use the $t$ statistics preferred by MacKinnon and Webb (2019).

${ }^{20}$ Randomization inference or permutation tests are increasingly being used in criminology applications like this one (see Kurland et al., 2014; Ridgeway \& MacDonald, 2017).
} 


\begin{tabular}{|c|c|c|c|c|c|}
\hline $\begin{array}{l}\text { Game Controls } \\
\text { Included }\end{array}$ & $\{-0.60,0.63\}$ & $\{-0.21,0.24\}$ & $\{-0.17,0.13\}$ & $\{-0.10,0.13\}$ & $\{-0.08,0.10\}$ \\
\hline \multicolumn{6}{|c|}{$\begin{array}{l}\text { Note: Each cell represents the coefficient on the treatment interaction (Extra Inning * Home Game * } \\
\text { CBP PSA) from a separate regression. In addition to this treatment interaction, each regression } \\
\text { includes the Extra Inning * CBP PSA and Home Game * CBP PSA interactions, as well as fixed effects } \\
\text { for each PSA and for each separate calendar day. In the regressions where length of game controls } \\
\text { are included, the following interactions are included in each regression: Game Length * Home Game * } \\
\text { CBP PSA and Game Length * CBP PSA. }\end{array}$} \\
\hline \multicolumn{6}{|c|}{$\begin{array}{l}\text { Data cover 2006-2015. Only regular season games are included in game data. Game days that } \\
\text { include a double header or games with rain delay time are excluded from the data. For games played } \\
\text { in the Eastern time zone, the time period covered is the time of the first pitch to the end of the game } \\
\text { plus one hour. For games played in different time zones, the time period covered is the time of the } \\
\text { first pitch converted to Eastern time through the end of the game plus one hour. For non-game days, } \\
\text { the time period covers 7:00 p.m. to } 11 \text { p.m. Standard errors clustered at PSA level. }\end{array}$} \\
\hline
\end{tabular}

Table 5 also shows results that when the regressions are restricted to only game days. For this specification the comparison now places the $9^{\text {th }}$ inning vs extra inning differential for a home game against the same differential for away games. Using this comparison, the coefficients barely change. In this comparison, the effect on total crime is statistically significant and represents about a $5 \%$ reduction in total crime.

Finally, table 5 shows results when the length of the game is controlled for. Longer games generate larger time windows which could mechanically measure more crime. While our comparisons with windows of the same duration in other areas of Philadelphia accounts for this, there may be heterogeneity in the time profile of crimes such that the CBP area sees more of its crime earlier in the day than do other areas. Accounting for the total duration of the game leads to larger decreases in the total crime effect, the effect on assaults, and the effect on liquor violations. This is true whether we include non-game days or not. However, as can be seen by the placebo critical values, standard inference approaches likely lead to over-rejection of the null effect. Using an empirical placebo distribution for inference, only the effects estimated for assaults are particularly large in magnitude. 
Focusing on extra innings, in some sense, leaves variation unexploited. As seen in Figure 1, while extra inning games are generally longer than 9 inning games, there is substantial overlap in the distributions of game duration.

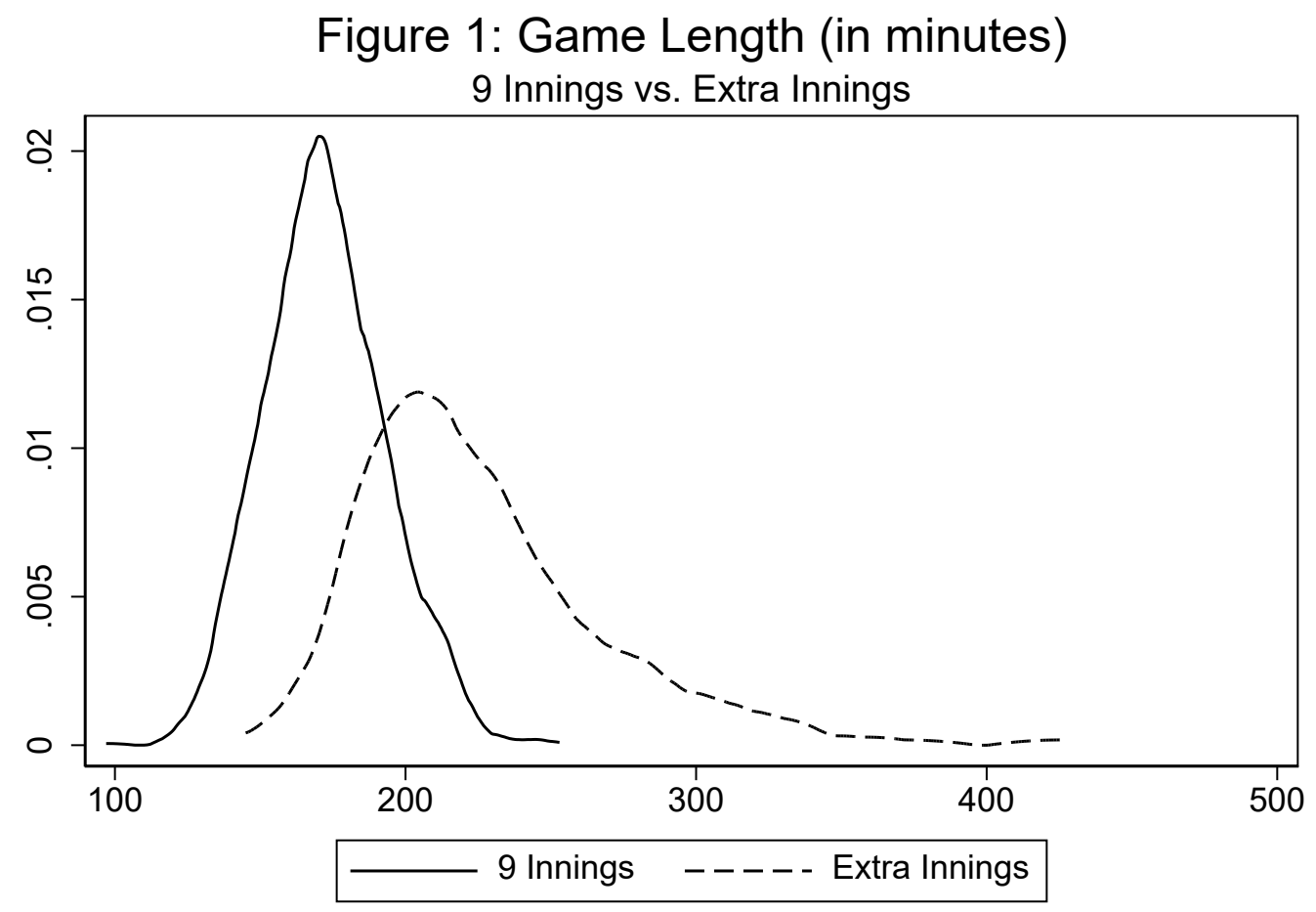

While it is not possible, using public data, to parse out how much game time occurs after the seventh inning, it is possible to know how many pitches were thrown by inning. Because there is a high correlation between pitches thrown and the game's duration $(\rho>0.92)$, we can use pitches as a time proxy, which we do in Table $6 .{ }^{21}$ For these regressions, the treatment effect is the interaction of Pitches Thrown After the $7^{\text {th }}$ Inning * Home Game * CBP PSA. These regressions also include the interactions Pitches Thrown After the $7^{\text {th }}$ Inning * CBP PSA and Home Game * CBP PSA, as well as the PSA and day specific fixed effects. To account for overall length, we also include Total Pitches Thrown * Home Game * CBP PSA and Total Pitches Thrown * CBP PSA. Given the earlier results, we focus only on assaults. The

\footnotetext{
${ }^{21}$ We only focus on game days since non game days cannot provide us with a pitches thrown number or a reliable proxy.
} 
importance of assaults in the existing literature likewise suggests assaults are a sensible place to focus our attention.

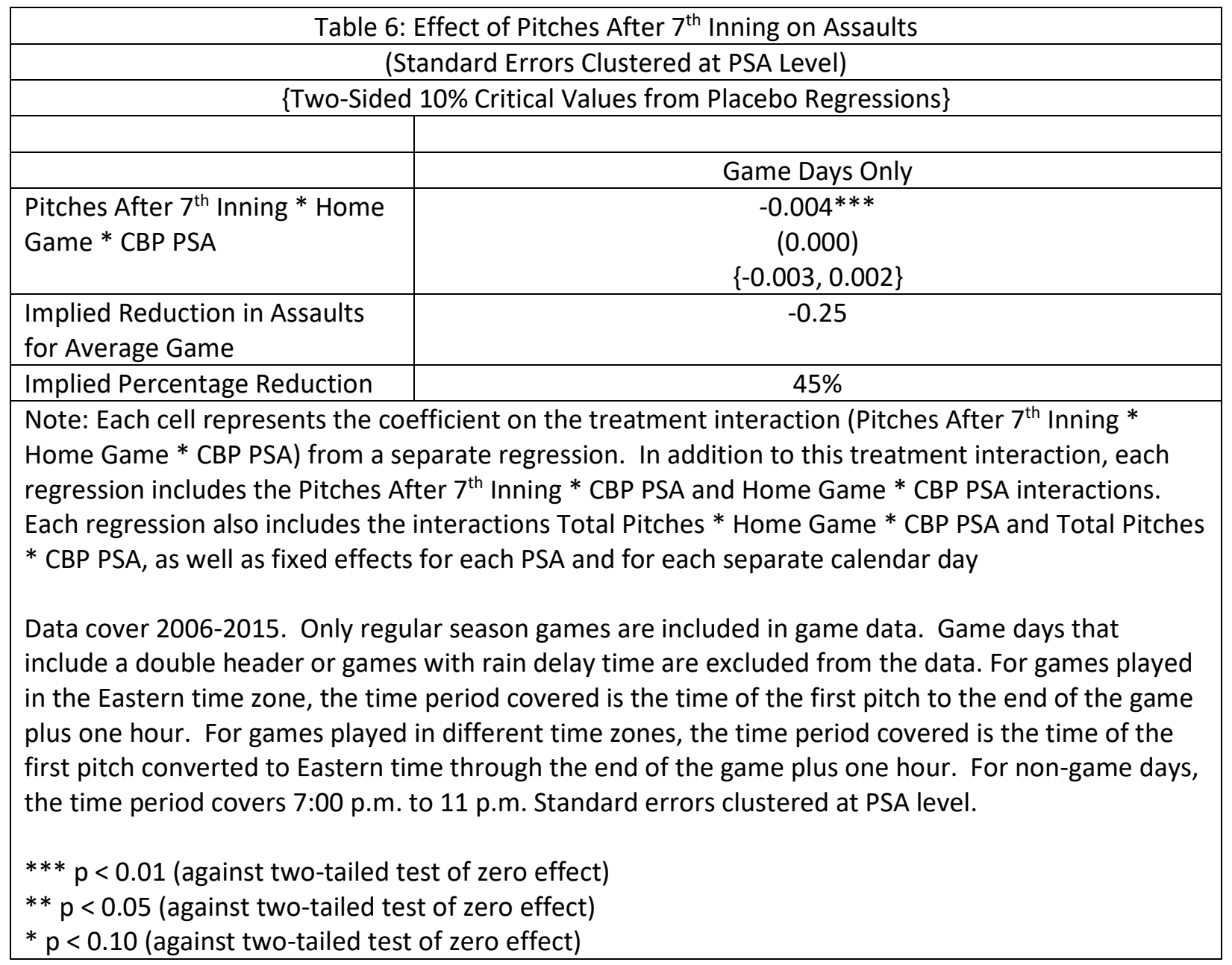

We estimate that each pitch thrown after the $7^{\text {th }}$ inning reduces assaults by almost 0.004 . Given that, on average, there are 68 pitches thrown after the alcohol policy goes into effect, this implies a reduction in assaults of about 0.25 , which is a proportionate reduction of almost one half. This effect is statistically significant using the standard approach to inference. Comparison to the distribution of placebo effects likewise suggests this effect was unlikely to have arisen by chance alone.

Philadelphia provides us with another source of variation. As discussed above, once Xfinity Live! Opens in March 2012, any benefits of the stadium's alcohol cut-off are likely to be undone as spectators 
now can now buy alcohol a few steps from the stadium no matter what inning it is. Table 7 shows results focusing on assaults, allowing for differential effects before and after the 2012 baseball season. We implement this in two different ways. First, we interact each of the previous effects with a dummy variable for whether Xfinity Live! was open or not. Secondly, we provide results where we split the sample into the pre-2012 period and the 2012 onward period. Both approaches yield the same implication. The effects we previously observed largely disappear once Xfinity Live! opens.

\begin{tabular}{|c|c|c|c|c|}
\hline \multicolumn{5}{|c|}{ Table 7: Assault Effect Before and After Xfinity Live Opens } \\
\hline \multicolumn{5}{|c|}{ (Standard Errors Clustered at PSA Level) } \\
\hline \multicolumn{5}{|c|}{ \{Two-Sided 10\% Critical Values from Placebo Regressions\} } \\
\hline & Full Sample & Full Sample & Before 2012 & After 2012 \\
\hline $\begin{array}{l}\text { Late Pitches * } \\
\text { Home }{ }^{*} \text { CBP }\end{array}$ & $\begin{array}{c}-0.004^{* * *} \\
(0.000) \\
\{-0.003,0.002\} \\
\end{array}$ & $\begin{array}{c}-0.007 * * * \\
(0.000) \\
\{-0.003,0.003\} \\
\end{array}$ & $\begin{array}{c}-0.006 * * * \\
(0.000) \\
\{-0.003,0.003\} \\
\end{array}$ & \\
\hline $\begin{array}{l}\text { Late Pitches * } \\
\text { Home }{ }^{*} \text { CBP * } \\
\text { Xfinity Live Open }\end{array}$ & & $\begin{array}{c}0.009 * * * \\
(0.000) \\
\{-0.005,0.005\}\end{array}$ & & $\begin{array}{c}0.001^{* * *} \\
(0.000) \\
\{-0.005,0.004\}\end{array}$ \\
\hline $\begin{array}{l}\text { All Covariates } \\
\text { Above Interacted } \\
\text { with Indicator for } \\
\text { Xfinity Live Open }\end{array}$ & No & Yes & No & No \\
\hline PSA Fixed Effects & Yes & Yes & Yes & Yes \\
\hline $\begin{array}{l}\text { Day Specific Fixed } \\
\text { Effects }\end{array}$ & Yes & Yes & Yes & Yes \\
\hline $\begin{array}{l}\text { Non Game Days } \\
\text { Included }\end{array}$ & No & No & No & No \\
\hline \multicolumn{5}{|c|}{$\begin{array}{l}\text { Note: Data cover 2006-2015. Only regular season games are included in game data. Game days that } \\
\text { include a double header or games with rain delay time are excluded from the data. For games played } \\
\text { in the Eastern time zone, the time period covered is the time of the first pitch to the end of the game } \\
\text { plus one hour. For games played in different time zones, the time period covered is the time of the } \\
\text { first pitch converted to Eastern time through the end of the game plus one hour. Xfinity Live opened } \\
\text { in the South Philadelphia Sports Complex (which includes Citizens Bank Park) parking lot in March } \\
2012 \text {. Standard errors clustered at PSA level. } \\
* * * p<0.01 \text { (against two-tailed test of zero effect) } \\
* * p<0.05 \text { (against two-tailed test of zero effect) } \\
* p<0.10 \text { (against two-tailed test of zero effect) }\end{array}$} \\
\hline
\end{tabular}

In the regression with the interaction, the pre-2012 effect of pitches after the $7^{\text {th }}$ inning is completely offset by the 2012 onward effect of pitches after the $7^{\text {th }}$ inning. In the split sample regressions, we 
observe our treatment effect in the pre-2012 sample, but we do not observe it in the sample covering 2012-2015. If anything, longer games are associated with an increase in assaults once Xfinity Live! opens.

\section{Effect Heterogeneity}

Table 8 provides estimates when the sample is split by weekend games (Friday-Saturday), weekday games (Sunday-Thursday), night games, when the Phillies win or lose, when a geographically close opponent is played, by attendance levels, ${ }^{22}$ and whether the game is tight. ${ }^{23}$ All estimates are presented for the full sample and before the opening of Xfinity Live.

\begin{tabular}{|l|c|c|}
\hline \multicolumn{2}{|c|}{ Table 8: Heterogeneity in Assault Effect } \\
\hline \multicolumn{2}{|c|}{ (Standard Errors Clustered at PSA Level) } \\
\hline \multicolumn{2}{|c|}{ \{Two-Sided 10\% Critical Values from Placebo Regressions\} } \\
\hline Full Sample & Full Sample & Before Xfinity Live! \\
& $-0.004^{* * *}$ & $-0.006^{* * *}$ \\
& $(0.000)$ & $(0.000)$ \\
\hline Friday \& Saturday Games Only & $\{-0.003,0.002\}$ & $\{-0.003,0.003\}$ \\
& $-0.006^{* * *}$ & $-0.009^{* * *}$ \\
& $(0.000)$ & $(0.001)$ \\
\hline Sunday-Thursday Games Only & $\{-0.005,0.004\}$ & $\{-0.007,0.007\}$ \\
& $-0.003^{* * *}$ & $-0.006^{* * *}$ \\
& $(0.000)$ & $(0.000)$ \\
\hline Night Games Only & $\{-0.003,0.003\}$ & $\{-0.005,0.004\}$ \\
& $-0.005^{* * *}$ & $-0.010^{* * *}$ \\
& $(0.000)$ & $(0.000)$ \\
\hline Day Games Only & $\{-0.004,0.003\}$ & $\{-0.004,0.004\}$ \\
\hline Friday \& Saturday Night Games Only & $-0.002^{* * *}$ & -0.001 \\
& $(0.000)$ & $(0.000)$ \\
& $\{-0.004,0.005\}$ & $\{-0.006,0.007\}$ \\
\hline Phillies Win & $-0.007^{* * *}$ & $-0.010^{* * *}$ \\
& $(0.000)$ & $(0.001)$ \\
& $\{-0.005,0.007\}$ & $\{-0.007,0.007\}$ \\
\hline & $-0.003^{* * *}$ & $-0.007^{* * *}$ \\
& $(0.000)$ & $(0.000)$ \\
& $\{-0.003,0.005\}$ & $-0.003^{* * *}$ \\
\hline
\end{tabular}

\footnotetext{
22 The $75^{\text {th }}$ percentile attendance level in CBP is 45,135 .

${ }^{23}$ We define a tight game as one that ends with a score differential of three runs or fewer. This tracks MLB's definition of a "close" game for the purposes of defining a save opportunity.
} 


\begin{tabular}{|c|c|c|}
\hline & $\begin{array}{c}(0.000) \\
\{-0.004,0.003\}\end{array}$ & $\begin{array}{c}(0.000) \\
\{-0.006,0.006\}\end{array}$ \\
\hline Geographically Close Opponent & $\begin{array}{c}-0.006^{* * *} \\
(0.000) \\
\{-0.005,0.007\} \\
\end{array}$ & $\begin{array}{c}-0.013^{* * *} \\
(0.000) \\
\{-0.005,0.007\}\end{array}$ \\
\hline Attendance Below $75^{\text {th }}$ Percentile & $\begin{array}{c}-0.002^{* * *} \\
(0.000) \\
\{-0.003,0.003\} \\
\end{array}$ & $\begin{array}{c}-0.005^{* * *} \\
(0.000) \\
\{-0.004,0.006\} \\
\end{array}$ \\
\hline Attendance Above $75^{\text {th }}$ Percentile & $\begin{array}{c}-0.006^{* * *} \\
(0.001) \\
\{-0.006,0.006\}\end{array}$ & $\begin{array}{c}-0.007 * * * \\
(0.001) \\
\{-0.008,0.007\}\end{array}$ \\
\hline Tight Game & $\begin{array}{c}-0.005^{* * *} \\
(0.000) \\
\{-0.003,0.003\} \\
\end{array}$ & $\begin{array}{c}-0.009 * * * \\
(0.000) \\
\{-0.004,0.004\} \\
\end{array}$ \\
\hline \multicolumn{3}{|c|}{$\begin{array}{l}\text { Note: Each cell provides the coefficient on the "Late Pitches * Home * CBP PSA" term and each } \\
\text { regression includes controls for "Late Pitches * CBP PSA," "Home * CBP PSA," "Total Pitches * Home * } \\
\text { CBP PSA," and "Total Pitches * CBP PSA" terms, as well as date specific fixed effects and PSA specific } \\
\text { fixed effects. Data cover 2006-2015. Only regular season games are included in game data. Game } \\
\text { days that include a double header or games with rain delay time are excluded from the data. Non } \\
\text { game days are excluded. For games played in the Eastern time zone, the time period covered is the } \\
\text { time of the first pitch to the end of the game plus one hour. For games played in different time zones, } \\
\text { the time period covered is the time of the first pitch converted to Eastern time through the end of the } \\
\text { game plus one hour. Xfinity Live opened in the South Philadelphia Sports Complex (which includes } \\
\text { Citizens Bank Park) parking lot in March } 2012 \text {. Geographically close opponents are the New York } \\
\text { Mets, the New York Yankees, the Baltimore Orioles, and the Washington Nationals. The time window } \\
\text { for each day includes the full span of the game plus } 1 \text { hour. Standard errors clustered at PSA level. } \\
* * * p<0.01 \text { (against two-tailed test of zero effect) } \\
* * p<0.05 \text { (against two-tailed test of zero effect) } \\
* p<0.10 \text { (against two-tailed test of zero effect) }\end{array}$} \\
\hline
\end{tabular}

Perhaps unsurprisingly, we see larger effects for nighttime and weekend games when, presumably, people are more inclined to drink excessively. There is some evidence that the effect is larger when the Phillies win and when they play a geographically close opponent, though we do not have much intuition for these results.

The differential attendance effects make sense as, presumably, more crowded games generate more social interaction. The fact that our result is larger in tight games is also helpful for building confidence that our result is driven by the alcohol sales restriction. One concern might be that as games 
last longer, people leave the CBP area before the end of the game, mechanically lowering assaults.

Presumably the potential for this is less when a game is more competitive.

Time Range of Effect

In the foregoing analyses, the time range studied on each game day runs from the time of the first pitch to the time of the last out plus 1 hour. Such analyses presume that any effect of the stadium alcohol policy will be temporally compact. To examine whether our estimated effect extends further in time, we re-run the basic regression allowing also for time windows that add 3 hours and 5 hours to the end of the game. The estimates of the basic treatment effects for each of these windows are presented in Figure 2 below.

Figure 2:

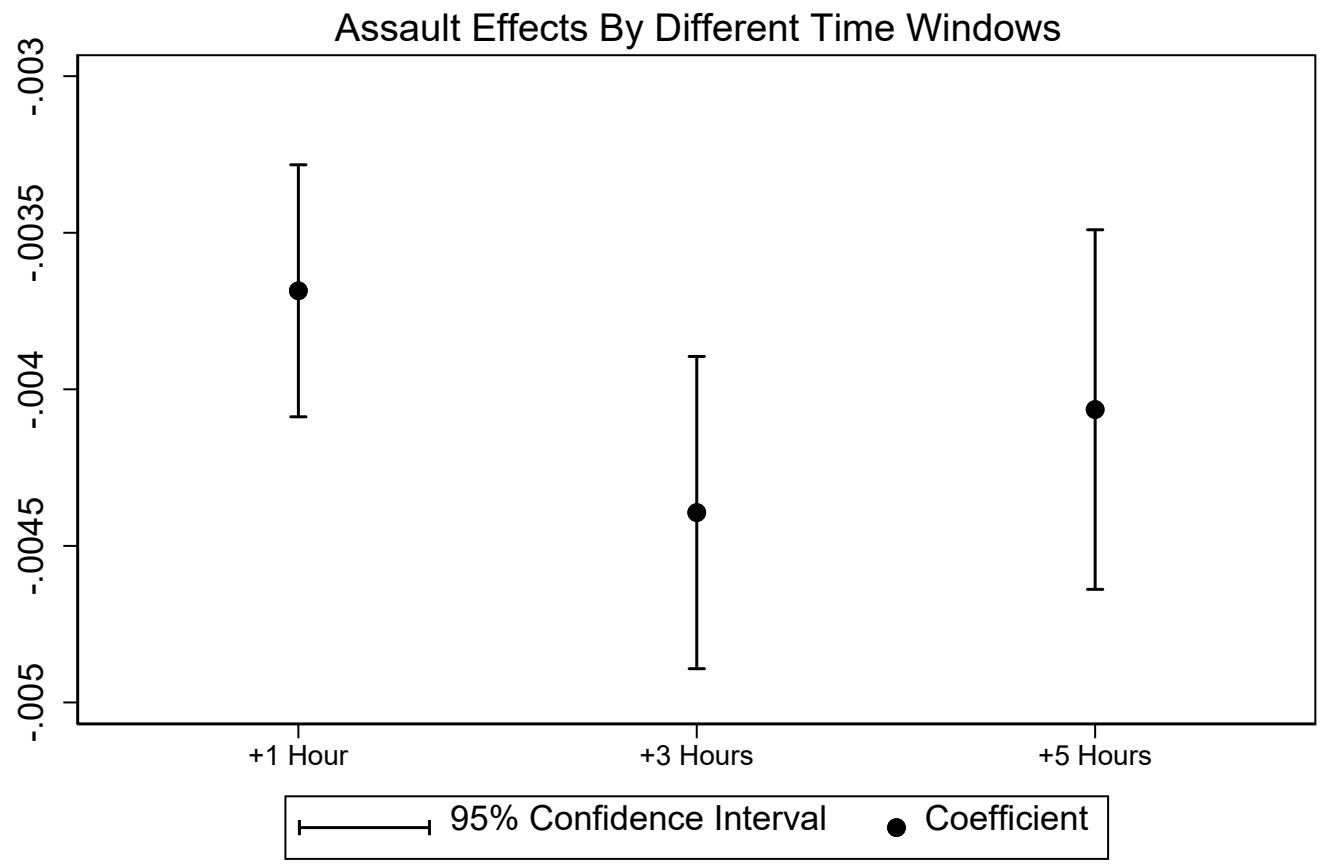

The confidence intervals for the coefficients using each of the three-time windows are overlapping, suggesting that the effect of the stadium alcohol policy on assaults is concentrated during the game time plus 1-hour period. 
Geographic Range of Effect

Until this point, we performed our analyses at the pre-defined Philadelphia Police PSA level.

While this approach has the benefit of using pre-determined geographic units of analysis, the PSA is, in a sense, over-inclusive, since it includes city blocks that are quite far from CBP. We constructed a CBP treatment area that better approximated the natural boundaries of the stadium. We aggregate crime in the area around the ballpark between I-76 in the North, I-95 in the South, Broad Street to the West, and a 1500 feet distance to the East. We then allocate all of the residual crime in CBP's PSA to its own geographic unit and keep all of the other PSAs constant. This re-organizing of the data allows us to construct a tighter boundary around the ballpark, perhaps shoring up confidence that any observed effect is driven by the drinking policy.

Table 9 shows results of regressions using this bespoke CBP boundary. The implied relative reduction in assault rates is larger than the one observed when the entire PSA is taken as the treatment area, suggesting that the assault generating effects of alcohol consumption in the stadium are highly localized. ${ }^{24}$

\begin{tabular}{|c|c|c|}
\hline \multicolumn{3}{|c|}{ Table 9: Assault Effect in Tighter Area Around Citizens Bank Park } \\
\hline \multicolumn{3}{|c|}{ (Standard Errors Clustered at PSA Level) } \\
\hline & Full Sample & Before Xfinity Live \\
\hline $\begin{array}{l}\text { Late Pitches * Home * CBP } \\
\text { Natural Boundary }\end{array}$ & $\begin{array}{c}-0.0009 * * * \\
(0.0002)\end{array}$ & $\begin{array}{c}-0.0012^{* * *} \\
(0.0003) \\
\end{array}$ \\
\hline $\begin{array}{l}\text { Implied Reduction in Assaults } \\
\text { for Average Game }\end{array}$ & -0.06 & -0.08 \\
\hline $\begin{array}{l}\text { Average Assault in CBP Natural } \\
\text { Boundary }\end{array}$ & $\begin{array}{c}0.1060 \\
(0.4139)\end{array}$ & $\begin{array}{c}0.1246 \\
(0.4346)\end{array}$ \\
\hline $\begin{array}{l}\text { Percentage Effect for Average } \\
\text { Number of Pitches After } 7^{\text {th }} \\
\text { Inning }\end{array}$ & $-58 \%$ & $-64 \%$ \\
\hline
\end{tabular}

${ }^{24}$ Given that the bespoke CBP area is substantially smaller than other PSAs (and has much less crime than virtually all of the PSAs due to its small area), we do not think the placebo inference approach is sensible with this analysis. 
fixed effects. Data cover 2006-2015. Only regular season games are included in game data. Game days that include a double header or games with rain delay time are excluded from the data. Non game days are excluded. For games played in the Eastern time zone, the time period covered is the time of the first pitch to the end of the game plus one hour. For games played in different time zones, the time period covered is the time of the first pitch converted to Eastern time through the end of the game plus one hour. Xfinity Live opened in the South Philadelphia Sports Complex (which includes Citizens Bank Park) parking lot in March 2012. The area around Citizens Bank Park goes West to Broad Street, South to I-95, North to I-76, and East for 1 mile. All Comparison PSAs are used, including the residual of the PSA that includes Citizens Bank Park.

$* * * p<0.01$ (against two-tailed test of zero effect)

$* * \mathrm{p}<0.05$ (against two-tailed test of zero effect)

$* p<0.10$ (against two-tailed test of zero effect)

While the results using the more natural CBP boundary are consistent with our previous results

and suggest that the assault effects are tightly concentrated around the stadium, our analysis is not

exactly an apples-to-apples one since the comparison geographic units are significantly larger than our

custom CBP unit. To address this, and to add a potentially more appropriate set of comparators, we

defined comparable boundaries around 10 popular sports bars throughout Philadelphia. Table 10

presents the results from the sports bars comparisons with comparable geographic boundaries.

\begin{tabular}{|c|c|c|}
\hline \multicolumn{3}{|c|}{ CBP Area Comp } \\
\hline \multicolumn{3}{|c|}{ (Standard Errors Clustered at Bar Level) } \\
\hline & Full Sample & Before Xfinity Live \\
\hline $\begin{array}{l}\text { Late Pitches * Home * CBP } \\
\text { Natural Boundary }\end{array}$ & $-0.0010^{* *}$ & \\
\hline \multicolumn{3}{|c|}{$\begin{array}{l}\text { Note: Each regression includes controls for "Late Pitches * CBP," "Home * CBP," "Total Pitches* } \\
\text { Home * CBP," and "Total Pitches * CBP" terms, as well as date specific fixed effects and bar area } \\
\text { specific fixed effects. Data cover 2006-2015. Only regular season games are included in game data. } \\
\text { Game days that include a double header or games with rain delay time are excluded from the data. } \\
\text { Non game days are excluded for games played in the Eastern time zone, the time period covered is } \\
\text { the time of the first pitch to the end of the game plus one hour. For games played in different time } \\
\text { zones, the time period covered is the time of the first pitch converted to Eastern time through the } \\
\text { end of the game plus one hour. Xfinity Live opened in the South Philadelphia Sports Complex (which } \\
\text { includes Citizens Bank Park) parking lot in March 2012. The area around Citizens Bank Park goes West } \\
\text { to Broad Street, South to I-95, North to I-76, and East for } 1 \text { mile. Comparisons are similar distances in } \\
\text { each direction around the following sports bars: Cavanaugh's (Center City); Cavanaugh's (University } \\
\text { City); Chickie's and Pete's (Robbins Avenue); Chickie's and Pete's (Roosevelt Avenue); Garage } \\
\text { Fishtown; Leneghan's Crusader Inn (Northeast); the Manayunk Tavern; McGillin's Olde Ale House } \\
\text { (Center City); Pub Webb (North Philadelphia); and Standard Tap (Northern Liberties). Standard errors } \\
\text { clustered on bar area. } \\
\text { *** p } 0.01 \text { (against two-tailed test of zero effect) }\end{array}$} \\
\hline
\end{tabular}




$$
\begin{aligned}
& * * p<0.05 \text { (against two-tailed test of zero effect) } \\
& * p<0.10 \text { (against two-tailed test of zero effect) }
\end{aligned}
$$

We find comparable statistically significant negative effects ${ }^{25}$ on assault even in this more tightly constructed comparison of sports bars. Since sports bars do not halt the sale of alcohol after the seventh inning, but are populated with sports fans, this comparison has the potential to account for any game-specific dynamics that could be related to assaults and whether the game extends for a long time after the seventh inning.

For one last alternate geographic unit definition, Table 11 shows the results when we aggregate crime counts to the Census block level. While Census blocks have the advantage of being predetermined, and they are tighter areas than the previously examined PSAs, the CBP Census block is not ideal since it includes a largely inaccessible area (the Eagles Nova Care Practice Complex), while severely restricting the eastern boundary of the CBP area. ${ }^{26}$ That notwithstanding, the results again show that assaults decline around CBP as games go longer after the seventh inning. In addition to comparing CBP with all other Census blocks, we also attempt to examine more appropriate comparators by looking at Census blocks that might be frequented by drinkers. To construct these comparisons, we look at Census blocks that have more than the mean number of total liquor licenses (8) associated with addresses in the Census block and those Census blocks that have at least one restaurant-based liquor license. ${ }^{27}$

\begin{tabular}{|l|c|c|}
\hline \multicolumn{3}{|c|}{ Table 11: Assault Effect in CBP Census Block } \\
\hline \multicolumn{3}{|c|}{ (Standard Errors Clustered at PSA Level) } \\
\hline \multicolumn{3}{|c|}{ \{Two-Sided 10\% Critical Values from Placebo Regressions\} } \\
\hline & Full Sample & Before Xfinity Live \\
\hline $\begin{array}{l}\text { Late Pitches * Home * CBP Census Block } \\
\text { (v. all Census Blocks) }\end{array}$ & $-0.0013^{* * *}$ & $-0.0011^{* * *}$ \\
\hline
\end{tabular}

\footnotetext{
25 Though the small number of bars limits the usefulness of a permutation inference approach here, it is possibly worth noting that the CBP effect is more negative than every placebo effect in the pre-2012 analysis. It is more negative than all but the effect estimated for McGillin's Olde Ale House when the entire time span is analyzed. ${ }^{26}$ The Census block eastern boundary is essentially the eastern wall of CBP.

${ }^{27}$ Many overall liquor licenses are assigned to social organizations that might not actually imply a high level of drinking (e.g., church groups), whereas restaurant-based liquor licenses likely indicate a consistent amount of drinking in the area.
} 


\begin{tabular}{|c|c|c|}
\hline & $\{-0.0006,0.0005\}$ & $\{-0.0007,0.0007\}$ \\
\hline $\begin{array}{l}\text { Late Pitches* Home * CBP Census Block } \\
\text { (v. Census Blocks with > } 8 \text { Total Liquor } \\
\text { Licenses) }\end{array}$ & $\begin{array}{c}-0.0013^{* * *} \\
(0.0001) \\
\{-0.0009,0.0006\}\end{array}$ & $\begin{array}{c}-0.0012 * * * \\
(0.0001) \\
\{-0.0012,0.0012\}\end{array}$ \\
\hline $\begin{array}{l}\text { Late Pitches * Home* CBP Census Block } \\
\text { (v. Census Blocks with > } 0 \text { Restaurant } \\
\text { Liquor Licenses) }\end{array}$ & $\begin{array}{c}-0.0013^{* * *} \\
(0.0000) \\
\{-0.0006,0.0006\}\end{array}$ & $\begin{array}{c}-0.0012^{* * *} \\
(0.0000) \\
\{-0.0008,0.0008\}\end{array}$ \\
\hline \multicolumn{3}{|c|}{$\begin{array}{l}\text { Note: Each cell represents the coefficient from a different regression. Each regression includes } \\
\text { controls for "Late Pitches * CBP Census Block," "Home * CBP Census Block," "Total Pitches * Home* } \\
\text { CBP Census Block," and "Total Pitches * CBP Census Block" terms, as well as date specific fixed effects } \\
\text { and census block specific fixed effects. Data cover 2006-2015. Only regular season games are } \\
\text { included in game data. Game days that include a double header or games with rain delay time are } \\
\text { excluded from the data. Non game days are excluded. For games played in the Eastern time zone, the } \\
\text { time period covered is the time of the first pitch to the end of the game plus one hour. For games } \\
\text { played in different time zones, the time period covered is the time of the first pitch converted to } \\
\text { Eastern time through the end of the game plus one hour. Xfinity Live opened in the South } \\
\text { Philadelphia Sports Complex (which includes Citizens Bank Park) parking lot in March 2012. Standard } \\
\text { errors clustered on Census Block. } \\
* * * p<0.01 \text { (against two-tailed test of zero effect) } \\
* * p<0.05 \text { (against two-tailed test of zero effect) } \\
* p<0.10 \text { (against two-tailed test of zero effect) }\end{array}$} \\
\hline
\end{tabular}

When examining the Census blocks, we again find that game time after the seventh inning is associated with a statistically significant reduction in assaults. The implied proportionate reduction in assaults is even larger than that implied in our previous analyses. This is true on average (an $89 \%$ reduction) and when we focus on Census blocks with a relatively high number of liquor licenses associated with them (an $87 \%$ reduction when compared to blocks with more than 8 total liquor licenses and a $91 \%$ reduction when compared to blocks with at least 1 restaurant liquor license).

\section{Conclusions}

This paper set out to examine the relationship between alcohol consumption and crime around a sports stadium. The seventh inning last call on alcohol sales provides a natural experiment to examine alcohol consumption and crime around a sports stadium. The un-timed nature of baseball games means that at some home games fans will have hours to sober up from drinking, whereas in others they may have only minutes from the last drink to they depart from the stadium. Philadelphia offered an 
additional natural experiment in that the Xfinity Live! complex opened in 2012 effectively undoing the limit on alcohol sales near the stadium. Our analysis included multiple comparisons of crime around the CBP stadium, all showing that assault offenses generally drop on home game days that extend into extra-innings. The effects are most pronounced at time windows closest to the end of the game, and the effect appears to be undone by the arrival of Xfinity Live! that allows fans to continue to purchase and drink alcohol on the stadium grounds. Like other crime and place studies (Kurland \& Johnson, 2019), we examine crime at multiple geographic levels, which allows us to see how robust the results are to different levels of aggregation.

Considering that assaults are considerably higher on game days near the CPB stadium when alcohol consumption and the end of the game are closer in time, this suggests that alcohol is a generator of assaults around the stadium that result in calls to the police. This effect is clear given that we see no similar reduction in crime around sports bars or other areas of Philadelphia when games go relatively long after the seventh inning. This work extends other research in suggesting that sports stadiums are crime generators (Billings \& Depken, 2011; Kurland, 2014; Marie, 2016; Kurkland \& Johnson, 2019; Vandeviver et al., 2019; Campaniello, 2013; Munyo \& Rossi, 2013), an effect that is likely enhanced by alcohol consumption. Stadiums with alcohol may then be considered one of many episodic crime generators in a city, much like bars that serve multiple drinks to patrons just before closing and let crowds hang around outside after closing (Graham et al. 2006; Graham \& Homel, 2012). These results lend further support for environmental criminology theories that emphasize situational opportunities that increase the risk for criminal offenses (Wilcox \& Cullen, 2019). Like the work by others that find sports stadiums are facilitators of crime nearby (Kurland \& Johnson, 2019), this work suggests that serving alcohol during MLB games closer the end of the game generates crime at stadiums around home games. 
This study suggests policy implications for the curtailing violence associated with drinking alcohol at baseball games. Considering the influence that serving alcohol closer to the end of the game has for amplifying assaults on home game days, with no evidence of similar effects elsewhere in Philadelphia, this implies a few potential avenues for policy. One implication is that more effort may be needed to minimize loitering of drunk people outside of the stadium at the end of the game.

Additionally, the presence of police in specific locations outside the stadium that are more often the presence of assaults may be warranted. Reducing queuing outside bars with rowdy patrons has been noted as an effective approach to reducing assaults (Graham \& Homel, 2012). And hot spot policing experiments shows that placing police temporarily in high crime locations helps thwart crime (Weisburd et al., 2012). Whether such approaches would be effective for reducing assaults around MLB stadiums warrants controlled field experiments, as both approaches may prove to be less costly than curtailing alcohol sales in stadiums.

The estimates from this study suggest that the last call for alcohol sales at the end of the seventh inning leads to a reduction of 0.25 assaults per game on average. McCollister, French, and Fang (2010) estimate that the social cost of an assault ranges between $\$ 24,000$ and $\$ 107,000$. This implies a benefit per home game between $\$ 6,000$ and $\$ 26,750$ of ending alcohol sales in the seventh inning. ${ }^{28}$ For the cost of the policy, we need some estimate of the welfare loss of not being able to drink from the seventh inning through the end of the game. Erickson et al (2011) suggests that about half of attendees at professional football and baseball games report drinking at the game with little difference between the two sports in terms of likelihood of drinking or the volume drank. While data on alcohol sales at baseball games are scarce, one source suggests that the Indianapolis Colts sold \$4 million in beer alone

\footnotetext{
${ }^{28}$ This number might need to be inflated to account for benefits of the policy beyond reduced assaults. Although our analyses suggest effects on other crimes might be limited, we did not examine DUI effects given that our highly localized place-based identification strategy is not credible in the DUI context. Carpenter and Dobkin's (2011) review indicates that a number of studies find beneficial effects of alcohol restrictions on the incidence of DUls.
} 
in its 11 home games in 2013, yielding a per game average of $\$ 364,000$. The Colts attendance in 2013 was twice as large as Phillies attendance over the course of our sample. A back of the envelope estimate of sales per Phillies game could then be $\$ 180,000$ per game, over 7 innings. This yields a per inning sales figure of $\$ 26,000$. Adding two more innings of beer sales would suggest revenue gains of $\$ 52,000$. For a welfare estimate, this number would need to be adjusted both for costs (cost of the beer itself, labor costs, etc.) and for consumer surplus (i.e., value derived from drinking the beer above the $\$ 6$ average price at $\mathrm{CBP}$ ). Taking a standard rule of thumb regarding profit margins on draft beer in the restaurant industry that suggests aiming for an 80 percent margin, even if consumers get zero surplus, the cost of the lost beer sales alone $(\$ 41,600)$ exceed the value of the assaults averted $(<\$ 27,000)$.

Reducing assaults is important, but it also depends on how much social value society sees from drinking at baseball games. These estimates also imply that efforts at managing crowds and where drunk people congregate at the end of games may be more cost-effective than curtailing alcohol sales in earlier innings. 


\section{References}

Anderson, D. M., Crost, B., \& Rees, D. I. (2018). Wet laws, drinking establishments and violent crime. The Economic Journal, 128(611), 1333-1366.

Brantingham, P., \& Brantingham, P. (1995). Criminality of place. European Journal on Criminal Policy and Research, 3(3), 5-26.

Callaghan, R. C., Gatley, J. M., Sanches, M., \& Benny, C. (2016). Do drinking-age laws have an impact on crime? Evidence from Canada, 2009-2013. Drug and Alcohol Dependence, 167, 67-74.

Cameron, A. C., Gelbach, J. B., \& Miller, D. L. (2008). Bootstrap-based improvements for inference with clustered errors. The Review of Economics and Statistics, 90(3), 414-427.

Campaniello, Nadia. 2013. Mega Events in Sports and Crime: Evidence From the 1990 Football World Cup. Journal of Sports Economics, 14(2): 148-170.

Carpenter, Christopher, and Carlos Dobkin. 2011. Alcohol Regulation and Crime in Controlling Crime: Strategies and Tradeoffs, Philip Cook, Jens Ludwig, and Justin McCrary, eds.

Carpenter, C., \& Dobkin, C. (2015). The minimum legal drinking age and crime. Review of economics and statistics, 97(2), 521-524.

Clarke, R. V. (1995). Situational crime prevention. Crime and Justice, 19, 91-150.

Cohen, L. E., \& Felson, M. (1979). Social change and crime rate trends: A routine activity approach. American Sociological Review, 588-608.

Conley, T. G., \& Taber, C. R. (2011). Inference with "difference in differences" with a small number of policy changes. The Review of Economics and Statistics, 93(1), 113-125.

Cook, P. J., \& Durrance, C. P. (2013). The virtuous tax: lifesaving and crime-prevention effects of the 1991 federal alcohol-tax increase. Journal of health economics, 32(1), 261-267.

Cook, P. J., \& Moore, M. J. (1993). Violence reduction through restrictions on alcohol availability. Alcohol Research, 17(2), 151.

Davies, T., \& Johnson, S. D. (2015). Examining the relationship between road structure and burglary risk via quantitative network analysis. Journal of Quantitative Criminology, 31(3), 481-507.

Erickson, D. J., Toomey, T. L., Lenk, K. M., Kilian, G. R., \& Fabian, L. E. (2011). Can we assess blood alcohol levels of attendees leaving professional sporting events? Alcoholism: Clinical and Experimental Research, 35(4), 689-694.

Ernst, M. D. (2004). Permutation methods: a basis for exact inference. Statistical Science, 19(4), 676-685.

Exum, M. L. (2002). The application and robustness of the rational choice perspective in the study of intoxicated and angry intentions to aggress. Criminology, 40(4), 933-966. 
Fagan, J. (1990). Intoxication and aggression. Crime and Justice, 13, 241-320.

Graham, K., Osgood, D. W., Zibrowski, E., Purcell, J., Gliksman, L., Leonard, K., \& Toomey, T. L. (2004). The effect of the Safer Bars programme on physical aggression in bars: results of a randomized controlled trial. Drug and alcohol review, 23(1), 31-41.

Graham, K., Bernards, S., Osgood, D. W., \& Wells, S. (2006). Bad nights or bad bars? Multi-level analysis of environmental predictors of aggression in late-night large-capacity bars and clubs. Addiction, 101(11), 1569-1580.

Graham, K., \& Homel, R. (2012). Raising the bar. Routledge.

Han, S., Branas, C. C., \& MacDonald, J. M. (2016). The effect of a Sunday liquor-sales ban repeal on crime: a triple-difference analysis. Alcoholism: Clinical and Experimental Research, 40(5), 1111-1121.

Heaton, P. (2012). Sunday liquor laws and crime. Journal of Public Economics, 96(1-2), 42-52.

Humphreys, D. K., \& Eisner, M. P. (2010). Evaluating a natural experiment in alcohol policy: The Licensing Act (2003) and the requirement for attention to implementation. Criminology \& Public Policy, 9(1), 4167.

Humphreys, D. K., Eisner, M. P., \& Wiebe, D. J. (2013). Evaluating the impact of flexible alcohol trading hours on violence: an interrupted time series analysis. PloS one, 8(2).

Kurland, J., Johnson, S. D., \& Tilley, N. (2014). Offenses around stadiums: A natural experiment on crime attraction and generation. Journal of Research in Crime and Delinquency, 51(1), 5-28.

Kurland, J., \& Johnson, S. D. (2019). The Influence of Stadia and the Built Environment on the Spatial Distribution of Crime. Journal of Quantitative Criminology, 1-32.

MacKinnon, J. G., \& Webb, M. D. (2019). Wild bootstrap randomization inference for few treated clusters. The Econometrics of Complex Survey Data: Theory and Applications, ed. Kim P. Huynh, David Tomás Jacho-Chávez, and Gautam Tripathi, 39, 61-85.

Marie, O. (2016). Police and thieves in the stadium: measuring the (multiple) effects of football matches on crime. Journal of the Royal Statistical Society: Series A (Statistics in Society), 179(1), 273-292.

Matthews, K., Shepherd, J., \& Sivarajasingham, V. (2006). Violence-related injury and the price of beer in England and Wales. Applied Economics, 38(6), 661-670.

Merlo, L. J., Hong, J., \& Cottler, L. B. (2010). The association between alcohol-related arrests and college football game days. Drug and Alcohol Dependence, 106(1), 69-71.

McCollister, K. E., French, M. T., \& Fang, H. 2010. The cost of crime to society: new crime-specific estimates for policy and program evaluation. Drug and Alcohol Dependence, 108(1-2), 98-109. 
Norström, T., \& Skog, O. J. (2005). Saturday opening of alcohol retail shops in Sweden: an experiment in two phases. Addiction, 100(6), 767-776.

Olsson, O., \& Wikstrom, P. O. H. (1982). Effects of the experimental Saturday closing of liquor retail stores in Sweden. Contemp. Drug Probs., 11, 325.

Rees, D. I., \& Schnepel, K. T. (2009). College football games and crime. Journal of Sports Economics, 10(1), 68-87.

Ridgeway, G., \& MacDonald, J. M. (2017). Effect of rail transit on crime: a study of Los Angeles from 1988 to 2014. Journal of Quantitative Criminology, 33(2), 277-291.

Sherman, L. W. (1992). Attacking crime: Police and crime control. Crime and Justice, 15, 159-230.

Sivarajasingam, V., Matthews, K., \& Shepherd, J. (2006). Price of beer and violence-related injury in England and Wales. Injury, 37(5), 388-394.

Vandeviver, C., Bernasco, W., \& Van Daele, S. (2019). Do sports stadiums generate crime on days without matches? A natural experiment on the delayed exploitation of criminal opportunities. Security Journal, 32(1), 1-19.

Weisburd, D., Maher, L., Sherman, L., Buerger, M., Cohn, E., \& Petrisino, A. (1992). Contrasting crime general and crime specific theory: The case of hot spots of crime. Advances in Criminological Theory, 4(1), 45-69.

Weisburd, D., Groff, E. R., \& Yang, S. M. (2012). The criminology of place: Street segments and our understanding of the crime problem. Oxford University Press.

Wilcox P, \& Gialopsos BM. (2015). Crime-event criminology: an overview. J. Contemp. Criminol. 31:4-11.

Wilcox, P., \& Cullen, F. T. (2018). Situational opportunity theories of crime. Annual Review of Criminology, 1, 123-148. 